\title{
Treatment of age-related subfoveal neovascular membranes by teletherapy: a pilot study
}

\author{
Usha Chakravarthy, Russell F Houston, Desmond B Archer
}

\begin{abstract}
This investigation was designed to determine whether low dose radiation to the macular region could influence the natural course of age-related subfoveal neovascularisation. Nineteen patients with subfoveal membranes due to age-related macular degeneration (ARMD) were treated with 10 or $15 \mathrm{~Gy}$ of $6 \mathrm{MV}$ photons and seven patients who declined treatment were followed up as controls. Six controls and all treated patients had completed follow up times of at least 12 months. Visual acuity was maintained or improved in $78 \%$ and $63 \%$ of treated patients at their 6 and 12 month follow up examinations respectively. By contrast visual acuity showed steady deterioration in six of seven controls. Significant neovascular membrane regression, as measured by image analysis, was recorded in $68 \%$ and $77 \%$ of treated patients at 6 and 12 months postradiation, whereas the membranes in all seven control patients showed progressive enlargement. This study suggests that low doses of radiation can maintain central vision and induce regression of subfoveal neovascular membranes of ARMD in a significant proportion of patients. We now believe it appropriate to proceed to a prospective randomised study to test this hypothesis further.

(Brf Ophthalmol 1993; 77: 265-273)
\end{abstract}

The visual prognosis for patients with subfoveal neovascular membranes (SNVM) in age-related macular degeneration (ARMD) is poor. ${ }^{12}$ Laser photocoagulation has been used to treat patients with subfoveal neovascular lesions with well demarcated boundaries. ${ }^{3}$ Although there is evidence that this results in some long term benefit, treated eyes experience an immediate decrease in visual acuity ( 3 lines on average), and treatment is only advocated if both the patient and ophthalmologist are prepared for 'a large decrease in visual acuity immediately following therapy.'3

Previously published reports have shown that ocular choroidal haemangiomas undergo regression when treated with $12 \mathrm{~Gy}$ of radiation from a $6 \mathrm{MV}$ photon beam. ${ }^{4}$ Recent experimental studies have shown that the neovascular component of healing ocular wounds are significantly reduced by doses in excess of $9.5 \mathrm{~Gy}$ of $\gamma$ radiation. ${ }^{56}$ It has also been concluded from studies of patients receiving cephalic teletherapy for orbital, paranasal, and nasopharyngeal tumours that eyes exposed to $25 \mathrm{~Gy}$ or less are unlikely to develop significant retinopathy. ${ }^{78}$ In view of the relative resistance of mature retinas to low doses of ionising radiation and the susceptibility of proliferating vascular cells to similar doses of radiation, we conducted a preliminary study to evaluate the effects of teletherapy on age-related subfoveal choroidal neovascular membranes.

\section{Patients and methods}

\section{SELECTION CRITERIA}

1 All patients at the date of entry to the study were 60 years of age or more and had agreed to regular follow up examinations, including fluorescein angiography.

2 All patients had progressive visual loss in the study eye with the best pretreatment corrected acuity no better than $6 / 24$ (Snellen chart).

3 All patients had SNVM, which had been identified by fluorescein angiography before therapy.

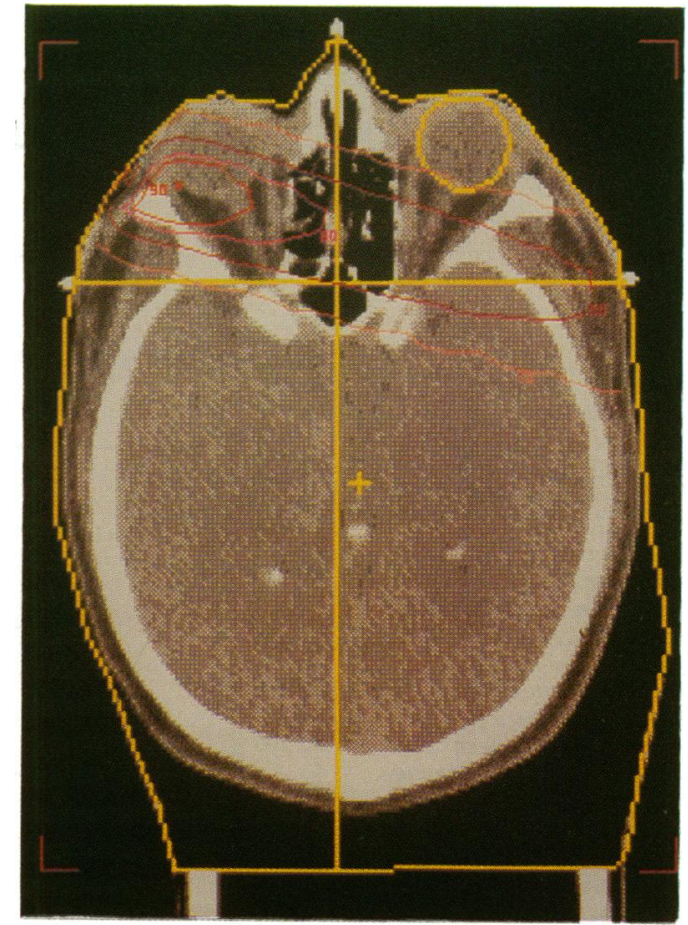

Figure I.CT scan with superimposed treatment plan showing isodose distribution for 6 MV photon beam. Note 90\% isodose encompassing right macula and optic disc (arrow). 


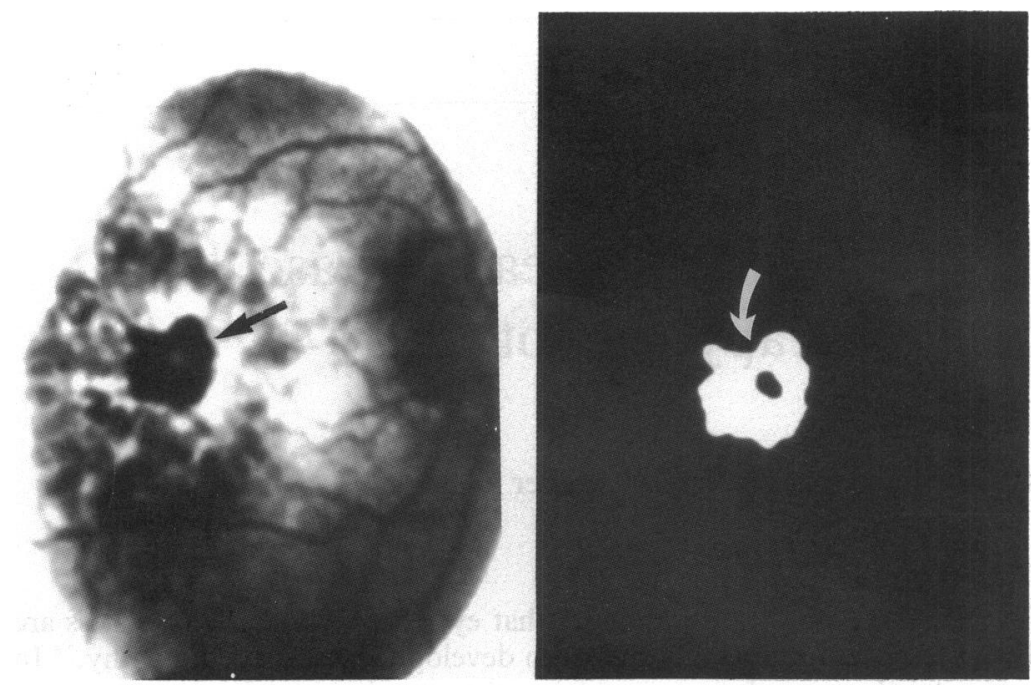

Figure 2 Fluorescein angiogram of patient No 24 viewed through a video camera showing a subfoveal neovascular membrane (arrow indicates the edge of the membrane and not the limit of the blood masking background fluorescence). Using image analyses, the area occupied by the NVM was quantitatively analysed (curved arrow).
Figure 3 (A) Fully corrected visual acuity as measured on the Snellen chart and plotted as a function of time (VA $10=6 / 12$ to $V A \quad l=1 / 60$ or worse, a change of 1 signifying a one line shift in acuity). In control patients visual acuity has dropped 2 lines by 12 months and decreased further by 18 months. In treated patients visual acuity has been maintained. (B) The change in area of the NVM represented as a proportion of that recorded in the preradiation angiogram using image analysis. The size of the NVM is reduced size of the NVM is reduced
to $50 \%$ of baseline in treated patients at 12 and 18 months post-radiation.
4 All neovascular membranes (NVM) entered into the study were considered unsuitable for laser photocoagulation by previously accepted criteria, ${ }^{9}$ and inappropriate for foveal ablation, ${ }^{3}$ on the basis that the patients counselled were not prepared to accept a treatment related sudden reduction in visual acuity in what was often their remaining serviceable eye.

5 Patients with recurrent subfoveal neovascularisation following treatment by laser photocoagulation were also entered into the study if the patient did not consent to foveal ablation.
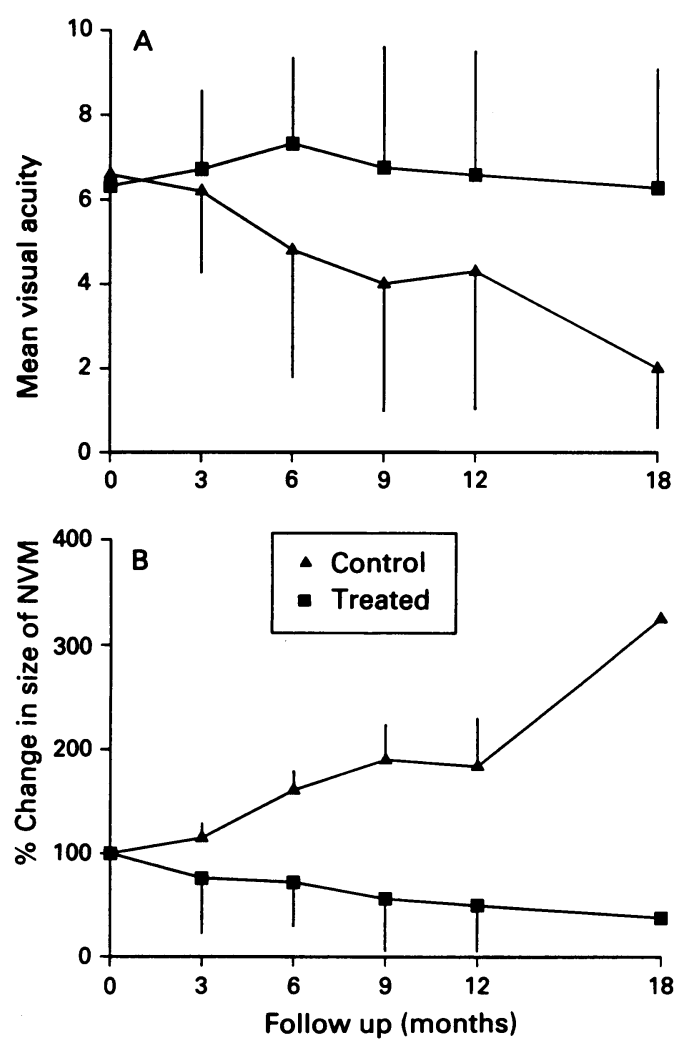

\section{Exclusion criteria}

1 Only one eye of any one patient was considered for radiotherapy.

2 Patients with stable vision (visual acuity unchanged over the preceding 12 weeks) were excluded from the study.

3 Patients with concomitant macular disease such as high myopia that might have contributed to visual loss were not entered into the study. Patients currently on oral medication - for example, cortiocosteroids, that might have affected visual functions and those with systemic vascular disease such as diabetes and uncontrolled hypertension or with ocular signs of vasculitis were also excluded.

The study population consisted of patients referred to the ophthalmic outpatient department of the Royal Victoria Hospital, Belfast. Patients were first recruited as possible candidates for radiotherapy following identification of an untreatable expanding SNVM involving the centre of the fovea by fluorescein angiography. A fully corrected near and distance visual acuity was obtained and ophthalmic examination carried out in which the clarity of the crystalline lens was specifically recorded. After pupillary dilatation the disc and macula were examined. Patients who were considered suitable for radiotherapy on the basis of the listed criteria were then fully counselled about the nature of their condition and offered radiotherapy. Nineteen patients consented to treatment by ionising radiation and seven patients, who declined radiotherapy but agreed to regular assessments, were followed as controls. The interval between diagnosis by angiography and treatment by radiotherapy was variable - that is, 2 weeks to 12 weeks, as some patients received laser therapy. Once the decision was made to treat by radiotherapy this was generally carried out within 2 weeks.

\section{Radiotherapy}

All patients who consented to radiotherapy were subjected to the following treatment protocol. Custom-made Perspex beam direction shells were made for each patient. A high definition computed tomography scan (CT scan) of the orbits was obtained. Cursor measurements were made from surface markers placed on the Perspex shell at the temporal region and the position of the posterior pole of the eye plotted from these measurements. Computer generated isodose curves for a single $6 \mathrm{MV}$ photon beam, given to $90 \%$ of the maximum dose, were superimposed onto the CT scan images (Fig 1). The 90\% isodose curve encompassed the macula and optic disc with less than $50 \%$ of the maximum dose falling on the posterior lens.

The first 11 patients received a dose of $10 \mathrm{~Gy}$ prescribed to the $90 \%$ isodose, delivered as five fractions of 2 Gy over 7 days. The next eight patients received $15 \mathrm{~Gy}$ as five fractions of $3 \mathrm{~Gy}$, also over 7 days. All eyes were irradiated through a single lateral port.

\section{Angiography}

On the day preceding radiotherapy a fluorescein 
Table 1 Details of visual acuity and angiographic changes during follow up

\begin{tabular}{|c|c|c|c|c|c|c|c|c|c|c|c|c|}
\hline \multirow[b]{2}{*}{ Patient } & \multirow[b]{2}{*}{ Age } & \multirow[b]{2}{*}{ Status } & \multirow[b]{2}{*}{$F U T$} & \multirow{2}{*}{$\begin{array}{l}\text { Initial } \\
V A\end{array}$} & \multicolumn{2}{|c|}{3 Months } & \multicolumn{2}{|c|}{6 Months } & \multicolumn{2}{|c|}{12 Months } & \multicolumn{2}{|c|}{18 Months or more } \\
\hline & & & & & $V A$ & $F A$ & $V A$ & $F A$ & $V A$ & $F A$ & $V A$ & $F A$ \\
\hline $\begin{array}{l}1 \\
2 \\
3 \\
4 \\
5 \\
6 \\
7 \\
8\end{array}$ & $\begin{array}{l}66 \\
63 \\
74 \\
64 \\
78 \\
81 \\
70 \\
66\end{array}$ & $\begin{array}{l}\mathrm{C} \\
\mathrm{C} \\
\mathrm{C} \\
\mathrm{C} \\
\mathrm{C} \\
\mathrm{C} \\
\mathrm{C} \\
15 \mathrm{~Gy}\end{array}$ & $\begin{array}{r}22 \\
20 \\
20 \\
20 \\
14 \\
12 \\
9 \\
12\end{array}$ & $\begin{array}{r}6 \\
7 \\
6 \\
4 \\
10 \\
6 \\
8 \\
7\end{array}$ & $\begin{array}{r}5 \\
7 \\
6 \\
4 \\
10 \\
6 \\
8 \\
6\end{array}$ & $\begin{array}{r}126 \\
120 \\
100 \\
103 \\
\\
104 \\
78\end{array}$ & $\begin{array}{r}3 \\
5 \\
6 \\
1 \\
10\end{array}$ & $\begin{array}{r}159 \\
180 \\
144 \\
127 \\
100 \\
27\end{array}$ & $\begin{array}{l}1 \\
2 \\
5 \\
1 \\
9 \\
4\end{array}$ & $\begin{array}{r}208 \\
195 \\
215 \\
141 \\
199 \\
228 \\
6\end{array}$ & $\begin{array}{l}1 \\
3\end{array}$ & $\begin{array}{l}200 \\
450\end{array}$ \\
\hline $\begin{array}{r}9 \\
10\end{array}$ & $\begin{array}{l}71 \\
60\end{array}$ & & & $\begin{array}{l}8 \\
8\end{array}$ & $\begin{array}{l}8 \\
9\end{array}$ & & $\begin{array}{l}6 \\
9\end{array}$ & $\begin{array}{r}94 \\
150\end{array}$ & $\begin{array}{l}6 \\
9\end{array}$ & 89 & 3 & 80 \\
\hline $\begin{array}{l}11 \\
12^{\star} \\
13\end{array}$ & $\begin{array}{l}62 \\
80 \\
70\end{array}$ & $\begin{array}{l}10 \mathrm{Gyt} \\
15 \mathrm{~Gy} \\
15 \mathrm{Gyt}\end{array}$ & $\begin{array}{l}20 \\
14 \\
16\end{array}$ & $\begin{array}{l}5 \\
6 \\
7\end{array}$ & $\begin{array}{l}6 \\
6 \\
7\end{array}$ & $\begin{array}{l}108 \\
100 \\
118\end{array}$ & $\begin{array}{r}4 \\
6 \\
10\end{array}$ & $\begin{array}{r}81 \\
118 \\
64\end{array}$ & $\begin{array}{r}3 \\
3 \\
11\end{array}$ & $\begin{array}{l}65 \\
86 \\
15\end{array}$ & 1 & 9 \\
\hline $\begin{array}{l}14 \\
15 \\
16\end{array}$ & $\begin{array}{l}70 \\
76 \\
75\end{array}$ & $\begin{array}{l}15 \mathrm{~Gy} \\
10 \mathrm{~Gy} \\
10 \mathrm{Gyt}\end{array}$ & $\begin{array}{l}18 \\
18 \\
21\end{array}$ & $\begin{array}{l}7 \\
5 \\
6\end{array}$ & $\begin{array}{l}9 \\
7 \\
6\end{array}$ & $\begin{array}{l}49 \\
80 \\
99\end{array}$ & $\begin{array}{l}9 \\
8 \\
6\end{array}$ & $\begin{array}{r}12 \\
81 \\
114 .\end{array}$ & $\begin{array}{r}10 \\
7 \\
6\end{array}$ & $\begin{array}{r}13 \\
79 \\
158\end{array}$ & $\begin{array}{l}7 \\
7 \\
6\end{array}$ & $\begin{array}{r}10 \\
67 \\
150\end{array}$ \\
\hline $\begin{array}{l}17 \\
18 \\
19\end{array}$ & $\begin{array}{l}70 \\
86 \\
67\end{array}$ & $\begin{array}{l}15 \mathrm{Gyt} \\
10 \mathrm{~Gy} \\
15 \mathrm{~Gy}\end{array}$ & $\begin{array}{l}12 \\
23 \\
14\end{array}$ & $\begin{array}{l}3 \\
3 \\
7\end{array}$ & $\begin{array}{l}3 \\
3 \\
7\end{array}$ & $\begin{array}{l}86 \\
90 \\
50\end{array}$ & $\begin{array}{l}6 \\
7 \\
7\end{array}$ & $\begin{array}{l}45 \\
90 \\
56\end{array}$ & $\begin{array}{l}1 \\
7 \\
2\end{array}$ & $\begin{array}{r}89 \\
17 \\
150\end{array}$ & 7 & 5 \\
\hline $\begin{array}{l}20 \\
21 \\
22\end{array}$ & $\begin{array}{l}88 \\
79 \\
63\end{array}$ & $\begin{array}{l}10 \mathrm{~Gy} \\
10 \mathrm{~Gy} \\
10 \mathrm{~Gy}\end{array}$ & $\begin{array}{l}21 \\
24 \\
24\end{array}$ & $\begin{array}{l}8 \\
6 \\
5\end{array}$ & $\begin{array}{l}8 \\
6 \\
2\end{array}$ & $\begin{array}{r}66 \\
55 \\
153\end{array}$ & $\begin{array}{l}9 \\
7 \\
2\end{array}$ & $\begin{array}{r}57 \\
18 \\
220\end{array}$ & $\begin{array}{l}9 \\
9 \\
3\end{array}$ & $\begin{array}{l}30 \\
15 \\
25\end{array}$ & $\begin{array}{l}9 \\
9 \\
3\end{array}$ & $\begin{array}{l}27 \\
11 \\
28\end{array}$ \\
\hline 23 & 81 & $15 \mathrm{~Gy}$ & 13 & 7 & 8 & 73 & 8 & 75 & 6 & 103 & & \\
\hline $\begin{array}{l}24 \\
25\end{array}$ & $\begin{array}{l}73 \\
73\end{array}$ & $\begin{array}{l}10 \mathrm{~Gy} \\
10 \mathrm{~Gy}\end{array}$ & $\begin{array}{l}24 \\
19\end{array}$ & $\begin{array}{l}6 \\
7\end{array}$ & $\begin{array}{l}7 \\
8\end{array}$ & $\begin{array}{l}71 \\
64\end{array}$ & $\begin{array}{l}9 \\
8\end{array}$ & $\begin{array}{l}34 \\
46\end{array}$ & $\begin{array}{l}9 \\
8\end{array}$ & $\begin{array}{r}6 \\
26\end{array}$ & $\begin{array}{l}9 \\
8\end{array}$ & $\begin{array}{l}16 \\
15\end{array}$ \\
\hline 26 & 66 & $15 \mathrm{~Gy}$ & 16 & 8 & 8 & 138 & 9 & 130 & 9 & 26 & & \\
\hline
\end{tabular}

^Patient developed posterior subcapsular lens opacification.

$\mathrm{C}$ = controls; FUT = follow up time in months; $\mathrm{VA}=$ visual acuity; $\mathrm{FA}=$ area of $\mathrm{NVM}$ represented as the percentage of that recorded in the pretreatment angiogram.

Angiographic data are not available for control patients at every follow up visit. Controls 3 and 4 have been lost to follow up.

Visual acuity: $1=1 / 60$ or worse, $2=2 / 60,3=3 / 60,4=4 / 60,5=5 / 60,6=6 / 60,7=6 / 36,8=6 / 24,9=6 / 18,10=6 / 12,11=6 / 9,12=6 / 7 \cdot 5$, $13=6 / 6,14=6 / 5,15=6 / 4$.

angiogram was performed in all but four patients and this provided the baseline for all subsequent measurements. In the four patients for whom this was not feasible, the most recent angiogram before radiotherapy was used for assessment.

\section{Patient follow up}

At each visit (scheduled for 1, 3, 6, 9, 12, 18, and 24 months post-radiation) best corrected visual acuity was measured using Snellen charts by the ophthalmologist, and ophthalmoscopic and biomicroscopic examinations were carried out. Colour photography of both maculas and fluorescein angiography of the posterior pole of the study eye were performed. These tests were also carried out at occasional extra unscheduled visits madeat the patient's request.

Selected frames from early to mid-venous phase angiograms taken before radiotherapy and at scheduled post-radiation visits were subjected to image analysis (Con-focal technologies, Fenestra software) and the area occupied by the neovascular membrane measured (Fig 2). The percentage change in size of the membrane with reference to the immediate preradiation angiogram was recorded at each time interval studied.

\section{Statistical methods}

Changes in visual acuity and membrane size from baseline to each follow up examination were the primary outcome variables which were analysed in treated patients and controls using the Kruskal Wallis test and the non-parametric MannWhitney U test.

\section{Results}

The minimum follow up time for patients reported in this study was 12 months with a median of 18 months. The mean follow up times for patients treated with $10 \mathrm{~Gy}$ and $15 \mathrm{~Gy}$ of radiation were 21.2 and 14.5 months respectively and that of control patients was 16.7 months. Data on visual acuity and angiographic changes at each assessment time are summarised in Table 1. The average age of the treated group was $72 \cdot 8$ years and that of controls $70 \cdot 8$ years.

\section{Visual acuity in the study eye}

There was no obvious difference in terms of visual outcome between patients who received 10 or $15 \mathrm{~Gy}$ of radiation. Mean changes in visual acuity during the period of the study are shown in Fig 3A. At 3 months, seven patients experienced an improvement of vision (defined as an increase of acuity of 1 whole line or more on the Snellen chart). In 10 patients there was no change and in two there was a decrease in vision (defined as a fall in acuity of 1 whole line or more on the Snellen chart). At 6 months, 12 patients showed an improvement in visual acuity, in three there was no change, and in four there was deterioration compared with baseline. At 12 months, visual acuity was improved in 10 and remained unchanged in two. Visual acuity was worse in seven patients of whom two experienced a 3 line loss on the Snellen chart compared with pretreatment acuity. In two of these patients continued leakage of dye and increasing size of NVM was documented post-radiotherapy. In one patient visual loss was attributed to posterior subcapsular lens opacification. This patient had received the higher dose ( $15 \mathrm{~Gy}$ ) of radiation (see Table 1).

Of the 11 patients who had 18 months' follow up or more, six had improved visual acuity, in two vision was maintained at pretreatment levels, and in three there was a fall in acuity associated with exudative changes in the macula. 


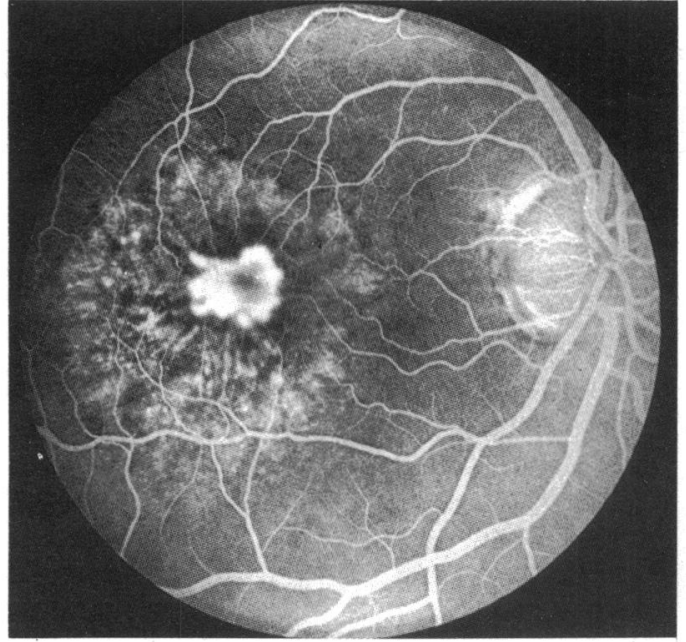

Fig $4 A$

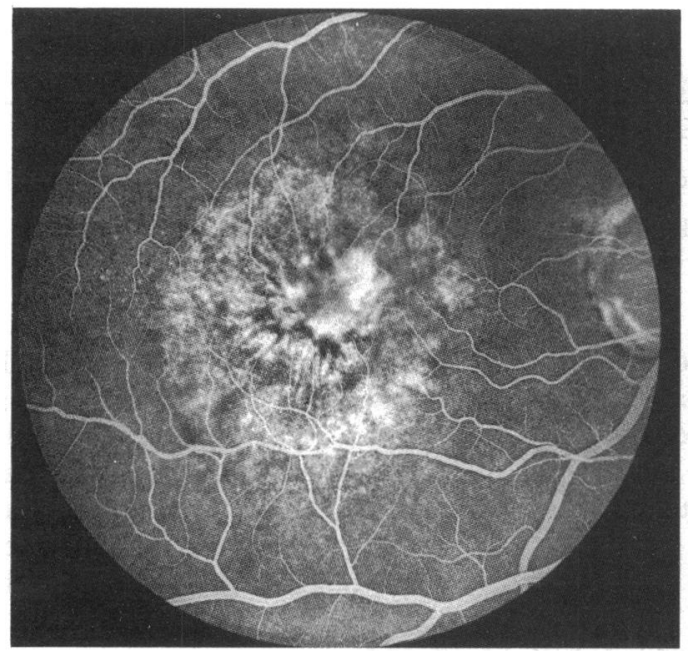

Fig 4 C

\section{Angiographic changes}

In all patients the neovascular membranes showed rapid increase in size in the interval between diagnosis and treatment. Following radiotherapy slower filling, reduced leakage, and membrane regression were features that were observable by 3 to 6 months post-radiation. Membrane regression was noted as early as 1 month and as late as 12 months (Fig 3B).

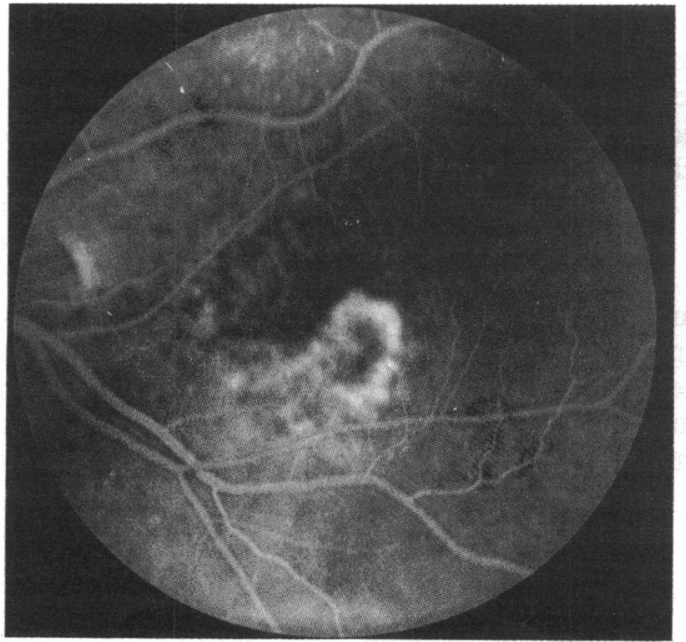

Fig 5 A

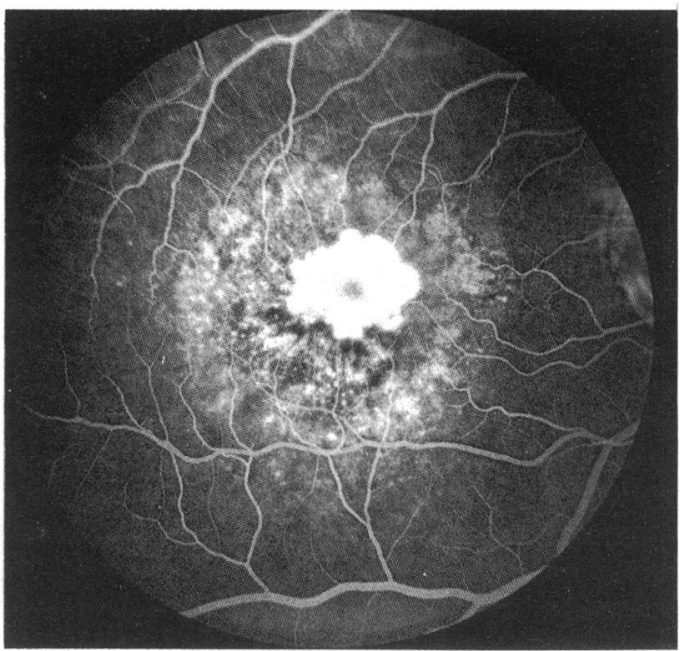

Fig $4 B$

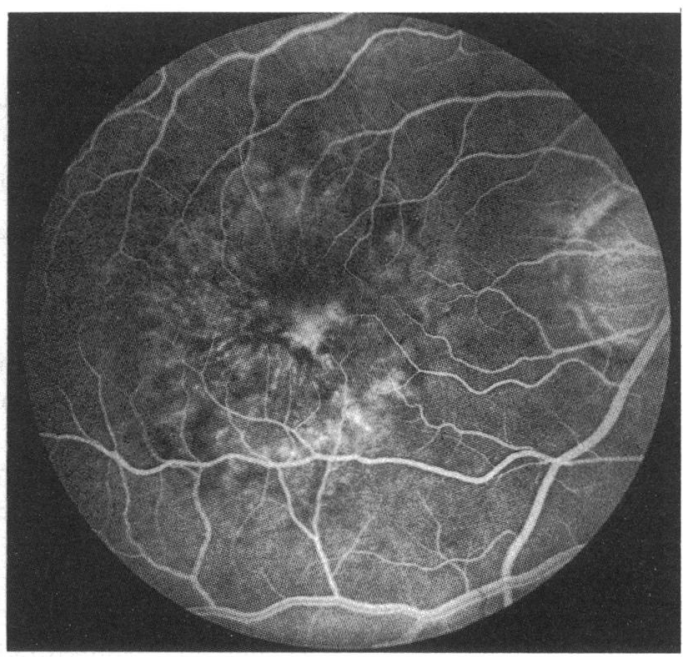

Fig $4 D$

At 3 months follow up, regression of the SNVM (defined as a decrease in size of the membrane of $10 \%$ or more from baseline) could be documented in 11 patients. In four patients no change was detected and in the remaining four an expansion of the membrane (an increase of $10 \%$ or more from baseline) had occurred. By 6 months, 13 patients $(68 \%)$ showed a reduction in the size of the membrane (Figs 4-7). In five

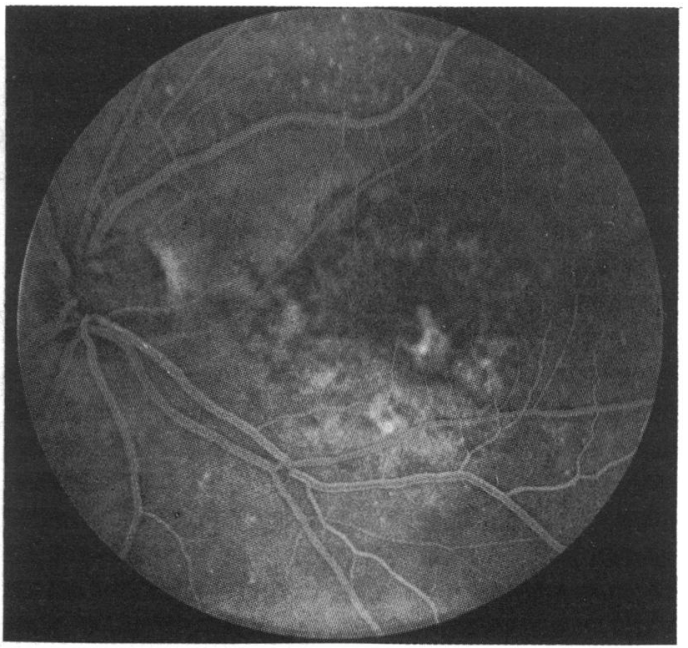

Fig $5 B$

Fig $5 B$ 


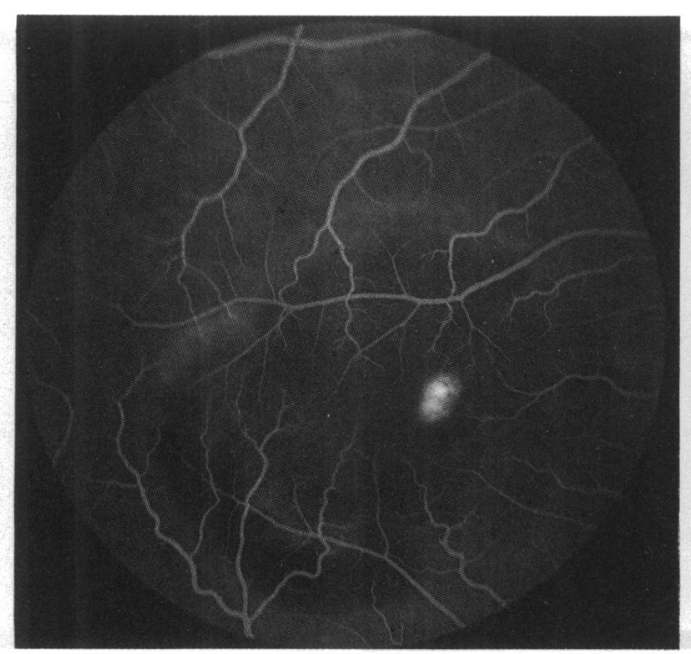

Fig $6 A$

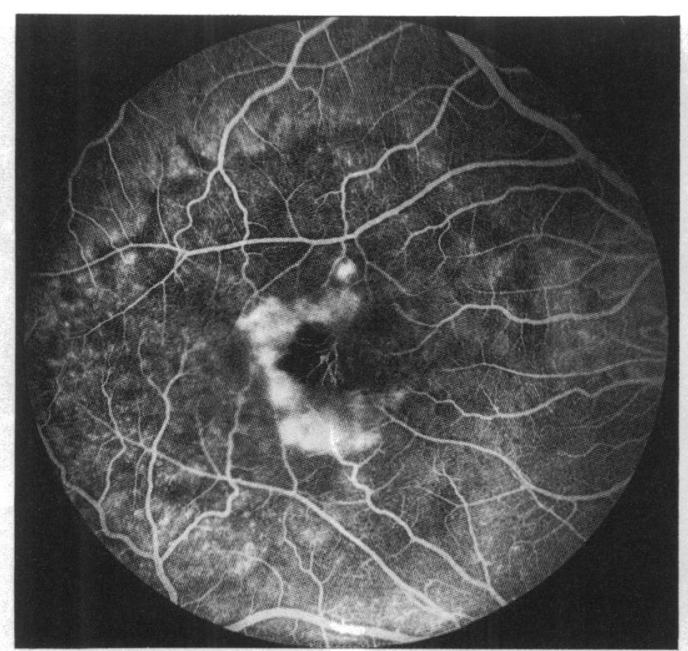

Fig $6 C$

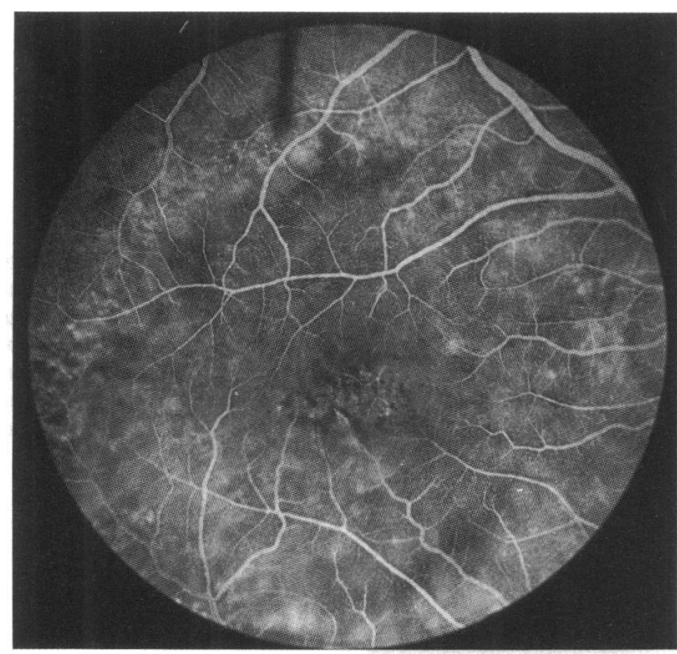

Fic $6 E$

patients the SNVM had increased in size and in one patient the SNVM remained unchanged following treatment. The regressing neovascular fronds were characterised by segmentation and loss of the peripheral capillary fringe, but the larger and more competent vessels tended to persist. Where atrophy was virtually complete, angiography revealed a hyperfluorescent focus at the initial site of the membrane.

At 12 months, 15 SNVMs (83\%) had regressed

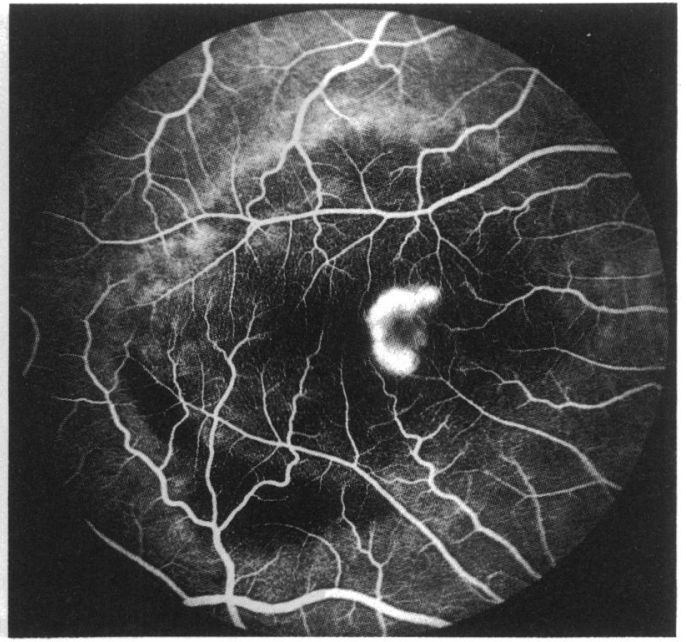

Fig $6 B$

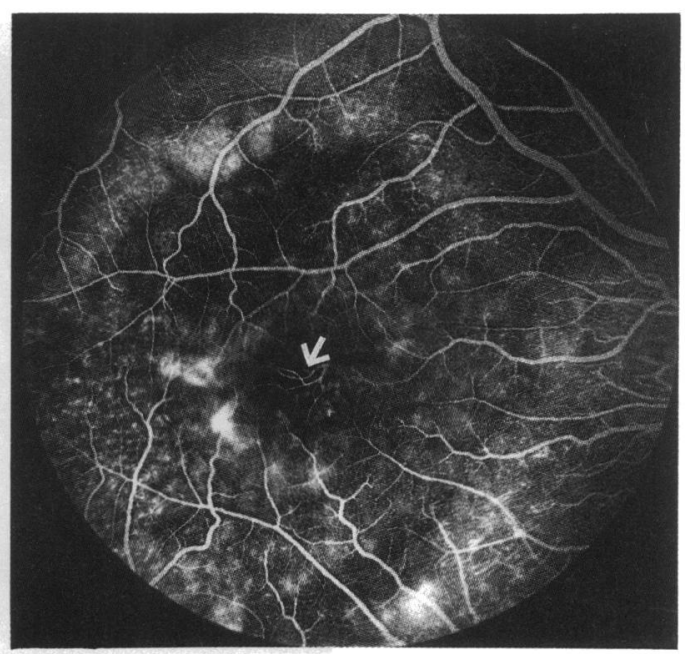

Fig $6 D$

Figure 6 Fluorescein angiograms of right fundus of patient 22 demonstrating a subfoveal NVM at presentation $(A)$ and 8 weeks later $(B)$ showing a rapidly enlarging neovascular membrane. Three months post-radiation the NVM has increased in size $(C)$. At 1 year post-radiation $(D)$ there is significant resolution of the NVM and at 2 years postradiation $(E)$ no discrete new vessels are identifiable. Residual choroidal trunk vessels are still present in $(D)$ but are competent to dye.

and in six of these there was almost complete disappearance of identifiable vessels. At 18 months' follow up all but one of the SNVM (11 patients) showed angiographic regression. There was no obvious relationship between the fate of the SNVM and the dose of radiation delivered.

\section{Macular morphology}

Before radiotherapy all patients had subretinal 


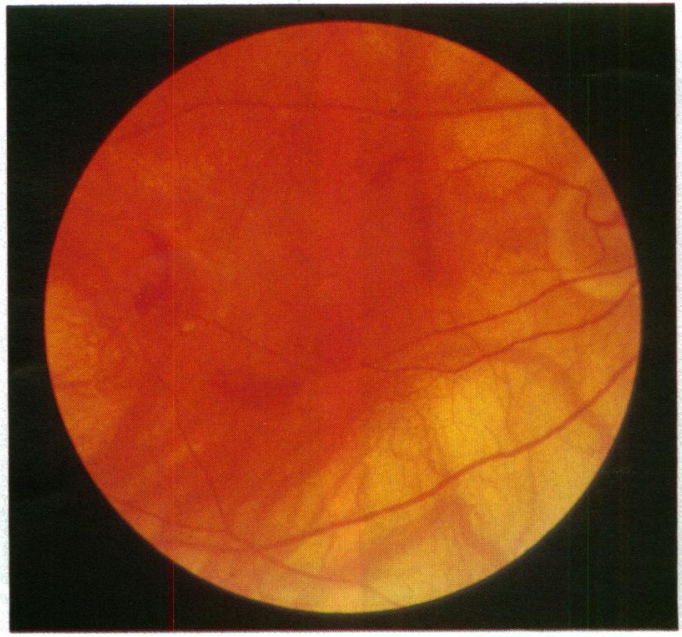

Fig $7 \mathrm{~A}$

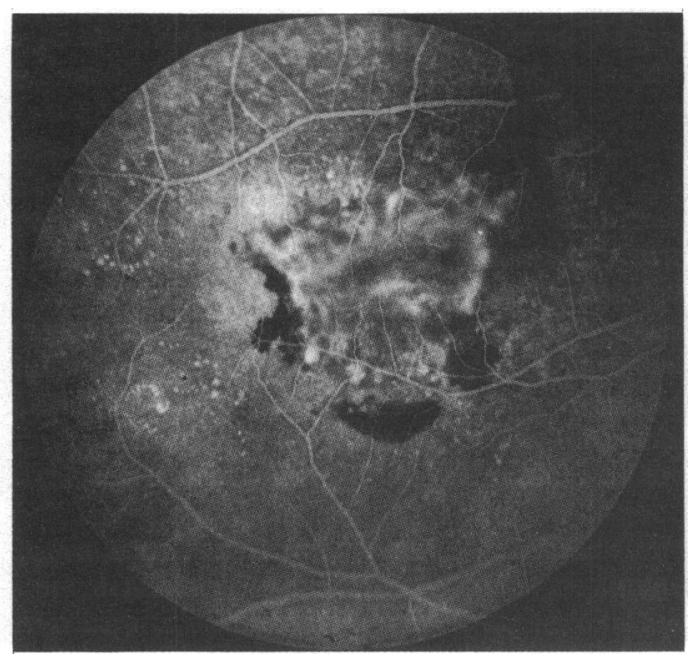

Fig $7 C$

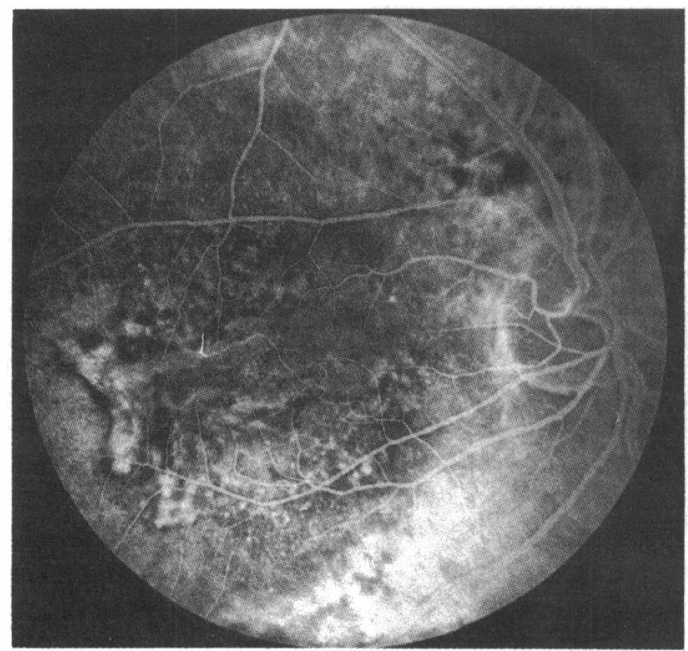

Fig $7 E$

fluid in association with the neovascular complexes and 10 had subretinal haemorrhage. Eight patients had retinal pigment epithelial detachments (RPED) and two had striking perifoveal exudates. These pathological changes resolved progressively in most patients following radiotherapy and correlated with regression of the neovascular membrane as demonstrated angiographically. At 12 months' follow up only three

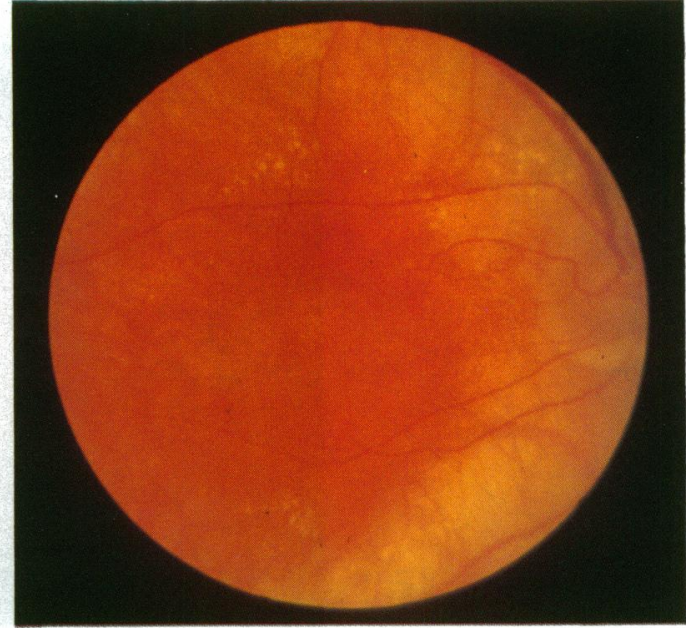

Fig $7 B$

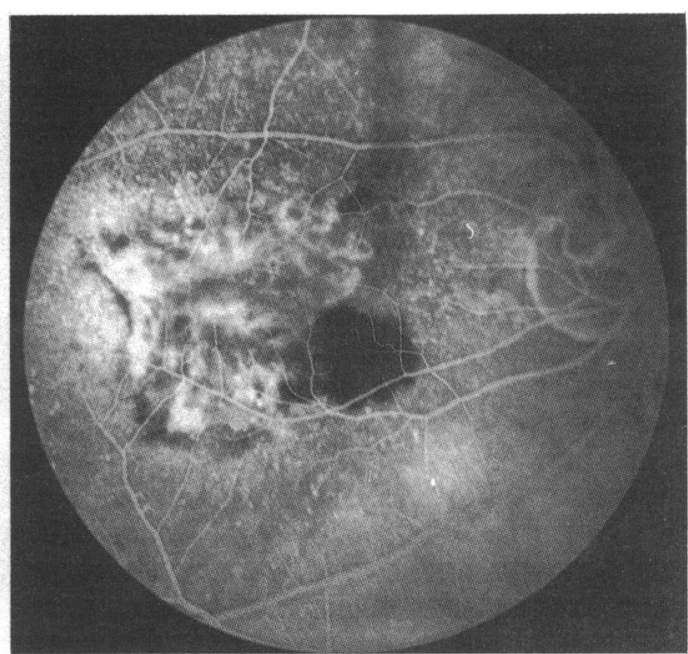

Fig $7 D$

Figure 7 Fundus photograph of right macula of patient No $25(A)$ immediately before and $(B) 1$ year post-radiotherapy. The disciform response is reduced and the subretinal haemorrhage has been absorbed. Fluorescein angiograms $(C)$ of macula shown in Fig $7 A,(D)$ Fig $7 B$ at 3 months, and $(E)$ at 12 months post-radiation. After an initial increase in the size of the NVM, significant regression has occurred.

patients showed persistent or recurrent subretinal haemorrhage which was associated with an expanding membrane as documented by angiography. All RPEDs resolved slowly, but in some instances taking up to 1 year to disappear. Ten patients showed evidence of macular fibrogliosis with two having an exuberant response. All treated maculas demonstrated signs of increased pigment proliferation within the atrophic scar. 
Figure 8 Fluorescein angiogram of a fundus of a control patient at

presentation $(A)$ and at 9

months' follow up $(B)$. The

NVM has doubled in size.

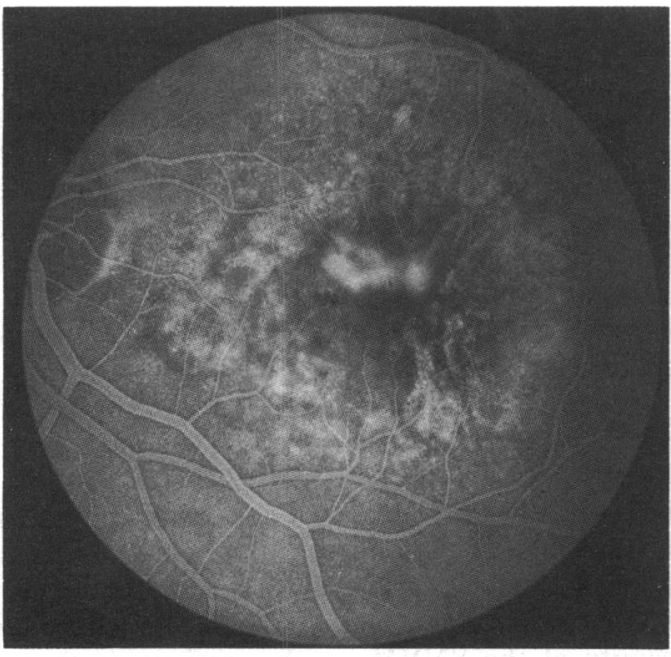

Fig $8 A$

During the period of the study none of the irradiated patients showed funduscopic or angiographic evidence of radiation induced vasculopathy.

\section{Control patients}

Six control patients were followed up for a period of 12 months and there was a mean reduction in visual acuity of 2.6 lines (Fig 3A) which was associated with a mean increase in size of the SNVM to $195 \%$ of baseline (Fig 3B). The fundus picture of these patients worsened significantly during the period of this study and fluorescein angiography showed progressive increase in size of the NVM (Fig 8). One further control, who was followed up for 9 months, maintained acuity at baseline level and an unchanged neovascular membrane on angiography. Two controls had follow up angiographic data at 18 months and the neovascular membranes had increased in size by $280 \%$ on average.

\section{Statistical analysis}

When data from treated patients were examined independently to reflect the two doses of radiation administered, there were no significant differences in visual acuity and angiographic appearances between the two treated groups at any time interval and between control and either of the treated groups at 3 months' follow up. Significant differences were present $(p<0.05)$ between control and each of the treated groups in terms of angiographic appearance at 6,9 , and 12 months. At 18 months the differences were not significant owing to the small numbers in each group. When data from the two treated groups were pooled there were significant differences in visual acuity $(p<0.05)$ and angiographic appearance $(p<0.01)$ between control and treated patients at 6,9 , and 12 months' follow up.

\section{Discussion}

Studies of the natural history of eyes with subfoveal neovascular membranes have shown that visual outcome is poor. ${ }^{12}$ The recent Macular Photocoagulation Study Group (MPS) study,

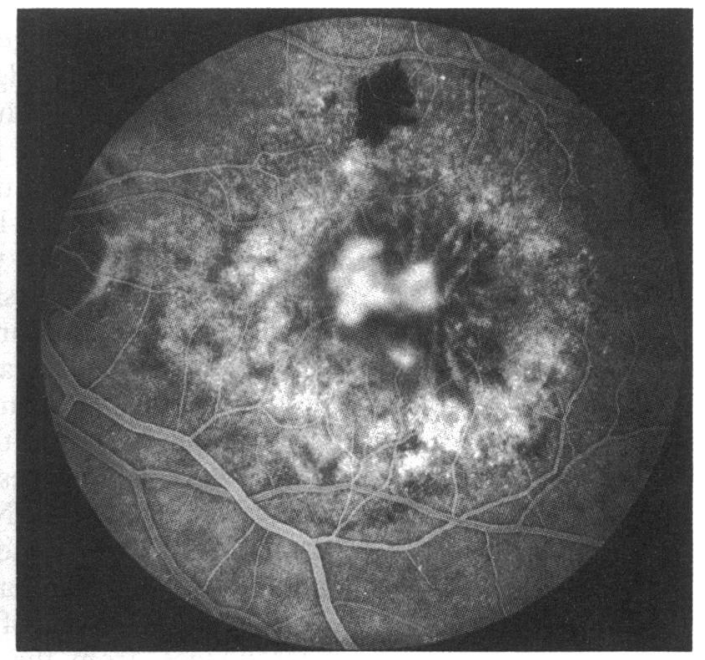

Fig $8 B$

which compared the results of foveal ablation using laser photocoagulation versus no treatment, reported that untreated eyes showed smaller decreases in visual acuity in the first 3 months of follow up than treated eyes. ${ }^{3}$ However, in the long term treated patients fared better than controls in terms of reading ability and central contrast sensitivity thresholds, and on average no visual benefit was observed until 18 months following treatment. ${ }^{3}$ Perifoveal laser photocoagulation of subfoveal neovascular lesions has also been shown to be effective in the short term preservation of visual acuity although the majority of patients (76\%) had suffered a six line visual loss by 42 months. ${ }^{10}$ These results amply illustrate the inexorable loss of vision which typically occurs in eyes with SNVMs and the limited therapeutic options available for patients presenting with, or developing, such membranes.

Inactive and self-limiting subretinal neovascularisation has been described in age-related macular degeneration by Jalkh et $a l^{11}$; however, these membranes were typically ill defined, showed minimal leakage of dye on fluorescein angiography, and occurred predominantly in patients over the age of 80 years. All the patients in our series had well defined membranes that leaked dye profusely into the subretinal space, and occurred on average in a younger age group (mean age $72 \cdot 3$ years).

Ionising radiation has a profound inhibitory effect on vascular endothelial cell proliferation in vitro, ${ }^{12}$ and single doses of $8 \cdot 7 \mathrm{~Gy}$ of $x$ rays prevent cell division in established human vascular endothelial cell cultures. ${ }^{13}$ Focal irradiation using plaques incorporating ${ }^{125} I$ seeds delivering doses in excess of $9.5 \mathrm{~Gy}$ can prevent the vascularisation of perforating scleral wounds in the rabbit. ${ }^{56}$ These observations along with evidence that mature retinal and choroidal vessels can sustain cumulative doses of radiation up to $25 \mathrm{~Gy}$ without observable damage, ${ }^{14}$ and that the retinal neuropile can survive similar or greater doses of fractionated radiation without permanent functional or structural changes, ${ }^{78}$ formed the basis for the use of radiotherapy in the treatment of proliferating SNVM of ARMD.

In the present work, radiotherapy had an inhibitory effect on subretinal neovascular mem- 
branes in $68 \%$ of treated patients by 6 months post-radiation, as judged by atrophy of capillaries at the growing edge and a decrease in the extent of dye leakage during fluorescein angiography. By 12 months' follow up the NVMs in $83 \%$ of patients had undergone considerable shrinkage although the larger and more competent feeding channels within the neovascular network tended to persist. Although the vasoocclusive response became obvious as a gradual shrinkage of the neovascular membrane at 6 months post-irradiation, occasionally a more rapid closure of part of the neovascular network occurred and was suggestive of infarction. Postradiation atrophy of the NVM probably occurred secondary to vascular endothelial cell death, local thrombosis, and capillary closure. ${ }^{14}$ It is also likely that removal of highly radiosensitive macrophages ${ }^{5}$ from the vicinity of the SNVM deprived the new vessels of vital cytokines necessary for growth and maintenance.

At the time of patient enrolment into the study most SNVMs were clearly defined on fluorescein angiography. However, in a small proportion of patients the neovascular membrane was not outlined in its entirety before radiotherapy, because of subretinal haemorrhage, pigment epithelial hypertrophy, or hyperplasia. Failure to measure the full extent of neovascularisation before treatment would have tended to underestimate the effect of radiotherapy and accordingly patients were not excluded on this basis.

Angiography was scheduled for all patients on the day preceding radiotherapy. However, this was not accomplished in four patients. In three patients (Nos $9,16,22)$ radiotherapy was undertaken within a few weeks of angiography. But in a fourth patient (No 24), 2 months had elapsed between angiography and treatment. In all patients immediate pre or pertreatment angiograms showed a significant increase in membrane size from the time of diagnosis, usually 2 to 12 weeks before radiotherapy. Hence the calculation of percentage change in membrane area in the four patients who did not undergo angiography just before radiotherapy probably resulted in an underestimation of the effect of treatment.

In the present study, a dose of $10 \mathrm{~Gy}$ was initially administered to patients and was chosen on the grounds of experimental evidence, ${ }^{5610}$ which suggested that actively replicating vascular endothelial cells would be sensitive to radiation levels in excess of $9 \mathrm{~Gy}$. However, membrane regression and improvement in vision was often not evident until 6 months after treatment and the dose was increased to $15 \mathrm{~Gy}$ in an attempt to promote an earlier response to therapy. Although this measure resulted in a more dramatic reduction in membrane size in two patients as judged by angiography at 3 months post-radiation, statistical analysis showed that the influence of dose change on membrane regression did not achieve significance at any of the time intervals studied. Also, comparison of visual acuities between patients who received $10 \mathrm{~Gy}$ or $15 \mathrm{~Gy}$ showed no significant differences at any point in the study.

Most patients who responded positively to radiotherapy had stable or improved visual acuity and enhanced reading vision at their 12 month follow up assessment $(63 \%)$. Stable or improved visual acuity generally correlated with regression of the neovascular membrane as documented by fluorescein angiography. In three patients, however, despite early evidence of membrane regression, continued deterioration of vision occurred. The reason for vision failure in these patients was not clear, although the presence of a large established membrane and pathological changes at the outer retina on treatment may have compromised visual function to an extent where recovery was not possible despite membrane regression. In one patient who had received the higher dose of $15 \mathrm{~Gy}$ visual decline was attributed to cataract formation. However, lens opacification did not appear to be a major problem following radiotherapy as none of the other patients in the series developed this complication. Even if cataract formation were a long term effect, it is eminently manageable and would be an acceptable complication in the event of a stabilised maculopathy.

One of the limitations of the present study is the relatively short follow up time although all treated patients had been followed for 1 year or longer. The randomised controlled MPS study comparing the effect of laser photocoagulation on subfoveal neovascular membranes showed that by 12 months' follow up the mean decrease in visual acuity in untreated eyes was 3.7 lines. ${ }^{15}$ All but one of the control patients in the present study showed a progressive loss of vision, which was consistent with results of the MPS study. In contrast, visual acuity in the majority of patients receiving radiotherapy was maintained or improved and was significantly different when compared with the control group.

The use of highly collimated beams of $6 \mathrm{MV}$ photons to treat the macula required accuracy of beam alignment and immobilisation of the patient and the eye. This was accomplished using a linear accelerator and a treatment plan that utilised a high definition CT scan to target the macula with the patient's head immobilised in a custom made mould. During treatment patients appreciated phosphene images which was confirmation that the retina was exposed to radiation.

This investigation was designed to determine whether low dose radiation to the macular region could influence the natural course of age-related subfoveal neovascularisation. This study provides evidence of a therapeutic effect, which in the majority of cases was positive and associated with stabilisation or slight improvement in central visual functions. We now believe it appropriate to proceed to a prospective randomised control study to test this hypothesis further.

The support from the Wellcome Trust is gratefully acknowledged. The authors also wish to thank Mr C Patterson (Queen's Univer sity of Belfast) for his assistance with the statistical analysis, and Miss M Burns (Northern Ireland Radiotherapy centre) for the organisation of and care given to patients receiving radiotherapy.

1 Bressler SB, Bressler NM, Fine SL, Hillis A, Murphy RP, Olk $\mathrm{JR}$, et al. Natural course of choroidal neovascular membranes within the foveal avascular zone in senile macular degeneration. Am $\mathcal{F}$ Ophthalmol 1982; 93: 157-63.

2 Guyer DR, Fine SL, Maguire MG, Hawkins BS, Owens SL Murphy RP. Sub-foveal choroidal neovascular membranes in age-related macular degeneration. Visual prognosis in eyes with relatively good visual acuity. Arch Ophthalmol 1986; 104: 702-5. 
3 Macular Photocoagulation Study Group. Laser photocoagulation of subfoveal neovascular lesions in age-related macular degeneration. Arch Ophthalmol 1991; 109: 1220-31.

4 Plowman PN, Harnett AN. Radiotherapy in benign orbital disease. I. Complicated ocular angiomas. Br $\mathcal{F}$ Ophthalmol 1986; $72: 286-8$.

5 Chakravarthy U, Gardiner TA, Archer DB, Maguire CJF. A light microscopic and autoradiographic study of nonirradiated and irradiated ocular wounds. Curr Eye Res 1989; 8: $337-48$.

6 Chakravarthy U, Biggart JH, Gardiner TA, Archer DB, Maguire CJF. Focal irradiation of perforating eye injuries: minimum effective dose and optimum time of irradiation. minimum effective dose and optir Eye Res 1989; 8: 1241-50.

7 Chan RC, Shukovsky LJ. Effects of irradiation on the eye. Radiology 1976; 120: 673-5.

8 Parsons JT, Fitzgerald CR, Hood CI, Ellingwood KE, Bova FJ, Million RR. The effects of irradiation on the eye and optic nerve. Int $\mathcal{F}$ Radiat Oncol Biol Phys 1983; 9: 609-22.

9 Macular Photocoagulation Study Group. Recurrent choroida neovascularization after argon laser photocoagulation for neovascular maculopathy. Arch Ophthalmol 1986; 104: 503-12.

10 Coscas G, Soubrane G, Ramahefasolo C, Fardeau C. Perifoveal laser treatment for subfoveal choroidal new vessels in agerelated macular degeneration: results of a randomized clinical trial. Arch Ophthalmol 1991; 109: 1258-65.

11 Jalkh AE, Nasrallah FP, Marinelli I, Van De Velde F. Inactive subretinal neovascularisation in age-related macular degeneration. Ophthalmology 1990; 97: 1614-9.

12 De Gowin RL, Lewis JL, Hoak JC, Mueller AL, Gibson DP. Radiosensitivity of human endothelial cells in culture. $\mathcal{F} \mathrm{Lab}$ Clin Med 1974; 84: 42-8.

13 Johnson LK, Longenecker JP, Fajardo LF. Differential radiation response of cultured endothelial cells and smooth myocytes. Anal Quant Cytol 1982; 4: 188-98.

14 Archer DB, Amoaku WMK, Gardiner TA. Radiation retinopathy, clinical, histological and ultrastructural correlations. Eye 1991; 5: 239-51.

15 Macular Photocoagulation Study Group. Laser photocoagulation of subfoveal recurrent neovascular lesions in age-related macular degeneration. Arch Ophthalmol 1991; 109: 1232-41. 